\title{
Analysis of Reaction and Mechanism of Incinerator Fly Ash Roasting
}

\author{
Mototsugu Matsuno ${ }^{(1)}$, Katsuhiro Tomoda ${ }^{(1)}$, Kouji Kawamoto ${ }^{(1)}$, and Takashi Nakamura ${ }^{(2)}$ \\ ('Sumitomo Metal Mining,Co., Ltd. \\ 11-3, 5-chome Shinbashi Minatoku Tokyo 105-8716 \\ Tel: +81-3-3436-7781; e-mail:Mototsugu_Matsuno@ni.smm.co.jp \\ ${ }^{(2)}$ Institute of Multidisciplinary Research for Advanced Materials, Tohoku University \\ 1,1katahira 2-chome, Aoba-ku, Sendai 980-8577, Japan
}

\begin{abstract}
Fly ash generated from a municipal waste incinerator is designated as a specially controlled substance in Japan, and it is obligatory to make it harmless before disposal. In a series of researches, we proposed a new treatment technology to make fly ash harmless. and performed thermodynamic investigations for removing major harmful heavy metals such as lead, cadmium, zinc, and chromium. This paper reports the strengthening mechanism of sintered pellets as treatment residue and the stabilization of minute residual heavy metals, centering on the effects of alkali salt and iron contained in the pellets as well as the effect of sintering in the pellet roasting process. Further, the development of advanced technologies is being required for recycling slag generated as byproducts from various smelting furnaces through effectively dealing with minute residual heavy metals contained in it, aiming at the steady expansion of its applications. This paper also reports the effectiveness of mixed treatment of incinerator fly ash and smelting slag.
\end{abstract}

Key Words: incinerator fly ash, heavy metal chloride volatilization, recycling, roasting method, rotary kiln.

\section{PURPOSE AND OUTLINE}

Fly ash generated from a municipal waste incinerator contains a large amount of heavy metals. As such, it is designated as a specially controlled substance in Japan, and it is obligatory to make it harmless before disposal. The effective use of residual contents is also important as one of the means to deal with the shortage of landfill disposal sites. The development of these recycling technologies for turning wastes into useful products is much in social need. The same is true of smelting slag. Achievements obtained through a series of researches we performed to date include the technology of roasting fly ash that contains a large amount of chlorine, the technology of removing heavy metals by volatilization, and the thermodynamic analysis of these technologies. Some of these achievements have been reported, or are going to be reported $19-11 \%$. It was reported in the past that the strength of sintered pellets is affected by the chemical composition, temperature, and reduction rate as well as the process conditions they undergo in a kiln $/ 1-8 /$. In this paper, each of these factors on sintered pellets is analyzed and the conditions for making strong pellets are clarified. The technology of simultaneous treatment of fly ash and smelting slag is also reported.

Incidentally, test equipment for verifying this technology was completed in 2000 and the verification test has been performed for about three years.

\section{FLOW OF THE NEWLY DEVELOPED PROCESS}

The process flow of the newly developed fly ash treatment technology is shown in Fig. 1. Generally, the treatment process consists of pellet forming, roasting, 


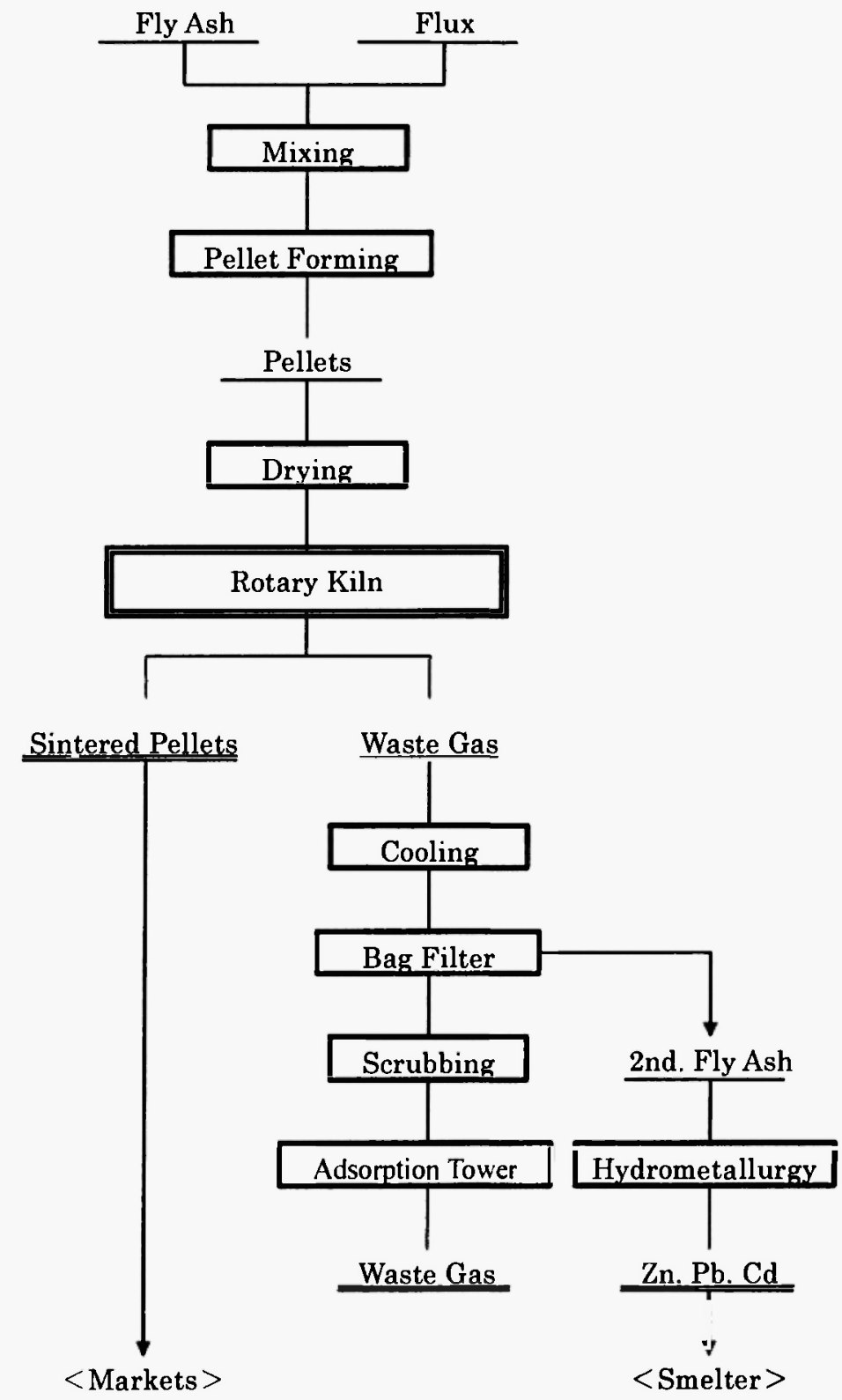

Fig. 1: Flow of tly ash treatment process

valuable metals recovery, and waste gas treatment.

\section{TEST EQUIPMENTAND METHOD}

A photograph of the verification test equipment and its schematic diagram are shown in Figs. 2 and 3. The test equipment is a kiln-type furnace. The incinerator fly ash was adjusted into a chemical composition in ccordance with the required test conditions in advance, mixed. and extrusion-formed into pellets, which were then dried and continuously charged into the kiln using a double-gate damper. The roasting temperature was basically set at more than $1000{ }^{\circ} \mathrm{C}$ to decompose dioxins, but below a temperature that causes mutual fusion of the pellets. A radiation thermometer was used 


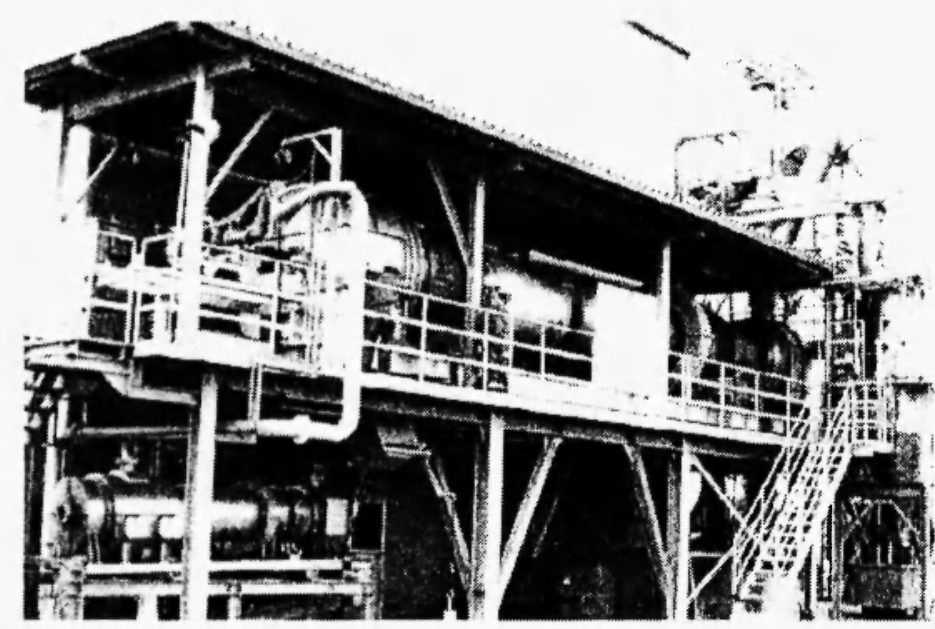

Fig. 2: Photograph of the kiln.

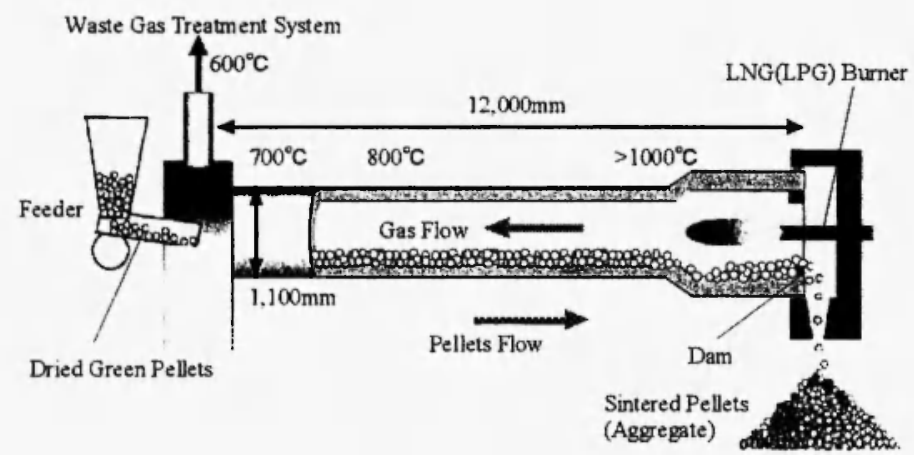

Fig. 3: Schematic diagram of the kiln.

to measure the temperature at the highest temperature zone in the kiln. This temperature was employed as a parameter for controlling the roasting process. Further. a series of fixed thermocouples were positioned at certain intervals along the length of the kiln for measuring and recording the temperatures to obtain the heat patterns in the kiln. The pellets and waste gas flow in the opposite directions in the kiln. A dam was installed at the discharging end of the kiln to maintain the bed layer. The length of time to retain the charged materials in the kiln was set at about two hours.

The strength of the sintered pellet was measured using a uniaxial crushing tester with a maximum load of $100 \mathrm{kgf}$. 20 pellets were random-sampled from each lot of pellets, and their average value was adopted as the strength of the said lot. The design capacity of the test equipment was $100 \mathrm{~kg} / \mathrm{h}$ with the kiln size of $900 \mathrm{~mm}$ in internal diameter and $12 \mathrm{~m}$ in length. $\mathrm{LPG}$ was used as heating fuel.

In the waste gas treatment system, the waste gas was rapidly cooled by water spraying at the kiln outlet. After secondary fly ash was collected by a bag filter, the waste gas was subjected to neutralization and activated carbon adsorption treatment before being released to the atmosphere.

The typical chemical compositions of the fly ash used in the tests are shown in Table 1 . These three distinctly different types of fly ash were used in the tests for the purpose of developing a technology that can deal with any type of fly ash. Different additives were used in accordance with test conditions, but basically small amounts of hematite, bentonite, and coke were used as additives. 
Table 1

Typical chemical compositions of the fly ash used in the tests (Unit :\%)

\begin{tabular}{|l|c|c|c|c|c|c|c|c|c|c|c|c|}
\hline $\begin{array}{l}\text { Type of } \\
\text { fly ash }\end{array}$ & $\mathrm{SiO}_{2}$ & $\mathrm{Al}_{2} \mathrm{O}_{3}$ & $\mathrm{Fe}_{2} \mathrm{O}_{3}$ & $\mathrm{CaO}$ & $\mathrm{MgO}$ & $\mathrm{Na}, \mathrm{O}$ & $\mathrm{K}_{2} \mathrm{O}$ & $\mathrm{ZnO}$ & $\mathrm{PbO}$ & $\mathrm{SO}_{3}$ & $\mathrm{Cl}$ & $\mathrm{C}$ \\
\hline $\begin{array}{l}\mathrm{A} \\
\text { (EP ash) }\end{array}$ & 10.2 & 5.8 & 1.3 & 15.8 & 2.9 & 12.7 & 12.0 & 1.3 & 0.2 & 10.8 & 23.8 & 0.8 \\
\hline $\begin{array}{l}\text { B } \\
\text { (Ca ash) }\end{array}$ & 1.3 & 3.5 & 0.8 & 39.6 & 4.3 & 3.9 & 4.0 & 0.3 & 0.1 & 3.7 & 13.3 & 1.9 \\
\hline $\begin{array}{l}\text { C } \\
\text { (EP ash) }\end{array}$ & 20.2 & 13.0 & 1.5 & 17.0 & 3.2 & 9.1 & 8.5 & 2.4 & 0.8 & 4.8 & 13.0 & 2.4 \\
\hline
\end{tabular}

EP ash: Ash collected with the electric precipitator

Ca ash: Ash collected with the bag filter to which slack lime was added.

\section{TEST RESULTS}

\subsection{Effect of chemical composition}

The chemical composition is a major factor that affects the pellet strength. By analyzing the results of the preliminary tests, detailed tests were carried out focusing on the alkali salt concentration. The results of the detailed tests are shown in Fig. 4. In this figure, chemical compositions of the green pellets were plotted on the ternary phase diagram of $\mathrm{Na}_{2} \mathrm{O}-\mathrm{SiO}_{2}-\mathrm{Al}_{2} \mathrm{O}_{3}$, and the levels of the strength after sintering were indicated by small squares and circles with different shades for easy distinetion. From the findings obtained through a series of investigations performed in the past. it was understood that, in the high alkali salt content region. it is difficult to perform high-temperature sintering and the obtainable strength is generally less than $30 \mathrm{kgf}$. The detailed tests, therefore, were performed this time

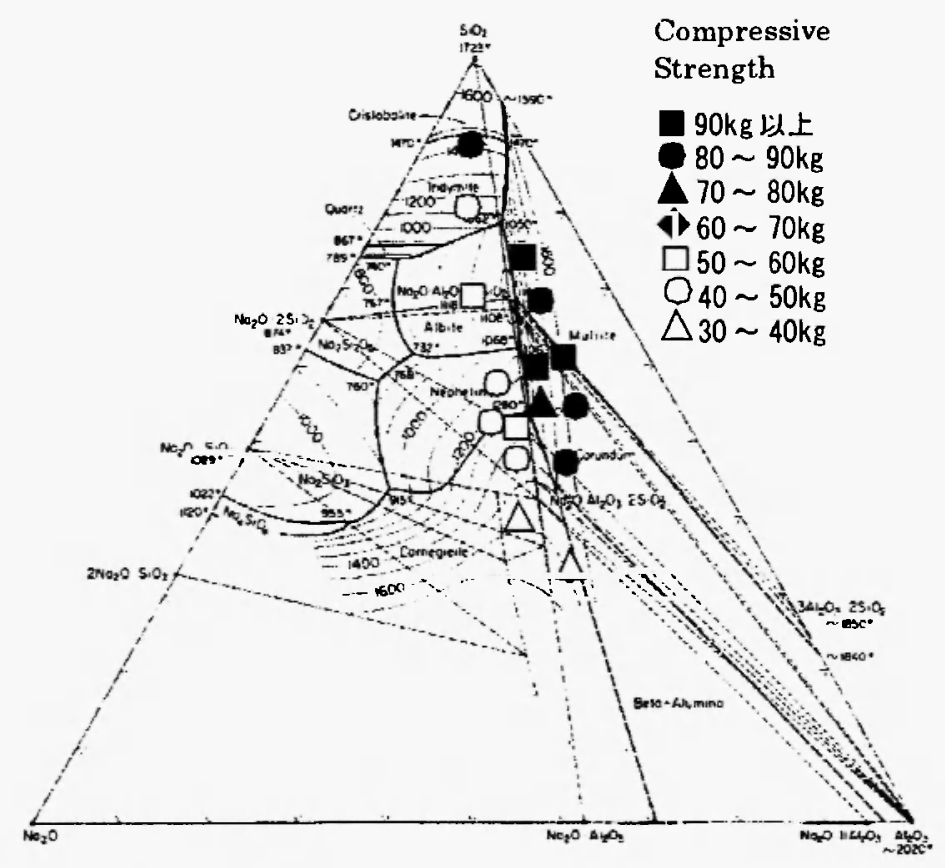

Fig. 4: Fxamined compositions \& strength results 
focusing on the compositional regions where comparatively high strength is easily obtainable. From this figure, it is apparent that comparatively high strengths are obtained in the vicinity of the eutectic line that lies in the low $\mathrm{Na}_{2} \mathrm{O}$ region.

\subsection{Effect of temperature}

In a series of verification tests, the roasting temperature was varied in accordance with the chemical composition adjusted for a specific test, but in principle it was set at a maximum temperature applicable to the roasting operation. However, in the tests to confirm the effect of the roasting temperature, the temperature setting was varied using the materials of the same chemical composition. An example of the relation between the roasting temperature and pellet strength is shown in Fig. 5, which was obtained from the tests using one of the materials with the standard chemical compositions; i.e., A (EP ash) in Table I. It is apparent that the pellet strength increases with increasing temperature over $1070^{\circ} \mathrm{C}$.

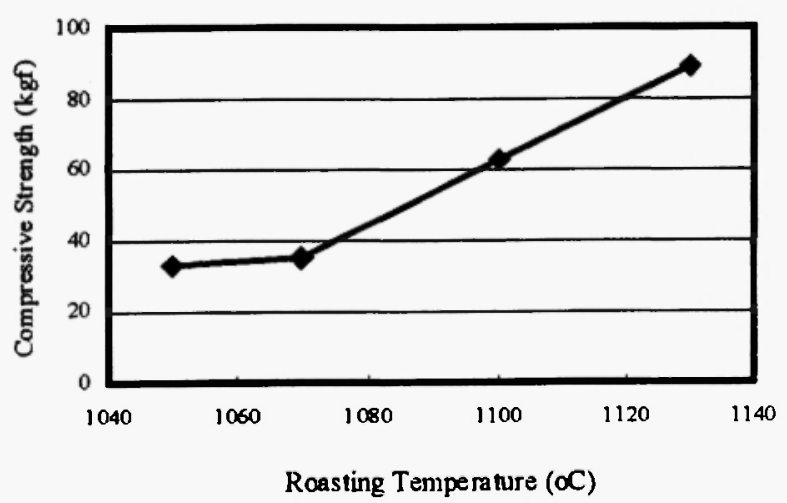

Fig. 5: Relation between baking temperature and baked pellet strength

\subsection{Effect of atmosphere}

The relation between the amount of residual carbon in the sintered pellet and the pellet strength is shown in Fig. 6. Pellets exhibit excellent strength when the amount of residual carbon is more than $0.1 \%$. In contrast, the strength delicately scatters when the amount of residual carbon is small, suggesting that the sintering did not make sufficient progress under these conditions.

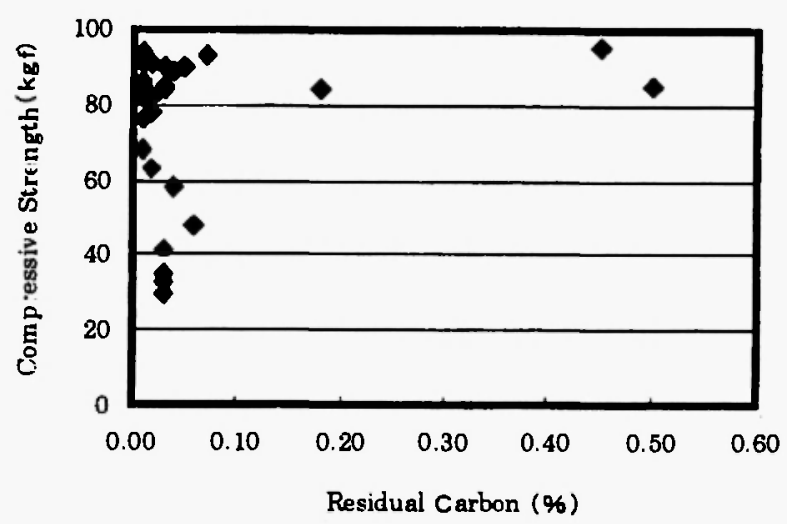

Fig. 6: Relation between residual carbon and sintered pellet strength

\section{DISCUSSION}

\subsection{Effect of chemical composition}

Alkali salt concentration $(\mathrm{Na}+\mathrm{K})$ has a large effect on the pellet strength as is apparent in Fig. 4. This effect was investigated more in detail. The results are shown in Fig. 7. The tests were performed using materials that had the $\mathrm{SiO}_{2} / \mathrm{Al}_{2} \mathrm{O}_{3}$ ratio of around $7 / 3$. The figure shows that the strengths of sintered pellets dramatically changes when the total of $(\mathrm{Na}+\mathrm{K})$ is increased beyond the level of around $8 \%$.

This phenomenon indicates that when $(\mathrm{Na}+\mathrm{K})$ concentration is increased beyond a certain limit, the chemical composition goes into the eutectic region. where the melting point is low and a large amount of the melt is generated. Therefore, in this region, it is not possible to raise the roasting temperature beyond a certain level, which in turn makes it difficult to promote the sintering.

The results shown in Figs. 4 and 7 confirm that the alkali salt concentration has a large effect and the roasting operation is extremely difficult when the chemical composition is on the high $(\mathrm{Na}+\mathrm{K})$ concentration side of the ternary phase diagram of $\mathrm{Na}_{2} \mathrm{O}-\mathrm{SiO}_{2}-\mathrm{Al}_{2} \mathrm{O}_{\hat{s}}$.

On the other hand, when the chemical composition is on the low $(\mathrm{Na}+\mathrm{K})$ concentration side, there exists a 


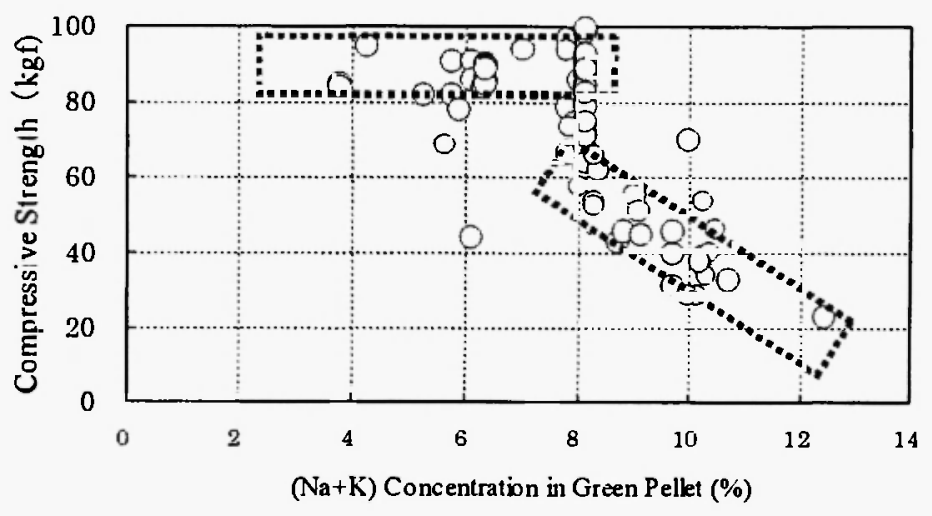

Fig. 7: Relation between salt concentration and sintered pellet strength

eutectic region with a comparatively high melting point on the slightly low $\mathrm{Na}_{2} \mathrm{O}$ side of the high melting point composition that includes albite. In this region, the molten body is generated in a comparatively high melting point region, and the amount of the melt generated by the temperature increase is small. The generated melt is absorbed into the pellet, which makes it difficult for the mutual fusion to take place at the pellet surface. Thus, it becomes possible to increase the roasting temperature and obtain sufficiently high pellet strength as shown in Fig. 5. The mechanism that causes this increase in strength was analyzed by observing the cross sections of pellets in the midst of the roasting process as described later. A photo of the sintered pellets is shown in Fig.8.

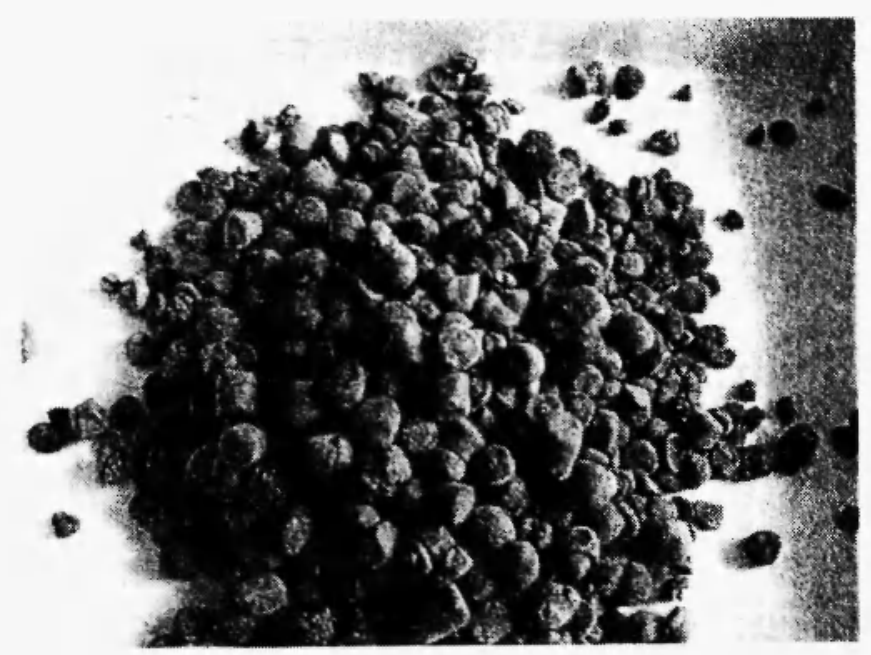

Fig.8: Photo of sintered pellets (diameter: around 10 $\mathrm{mm})$
From these results, it was verified that, regardless of the chemical composition of material ash, it is possible to apply the roasting operation to any ash by adding an. appropriate amount of additives and adjusting its composition into a proper region.

By X-RD. it was confirmed that the major compounds constituting a pellet include albite, gehlenite, nephline, and corundum. $\mathrm{SiO}_{2}$, and $\mathrm{CaO}$ were not detected in their single forms. Thus it was again verified that during the retaining time of two hours, sufficient reactions take place in the kiln for obtaining sintered pellets that are well stabilized.

It was also confirmed that the increase in the $\mathrm{CaO}$ content does not have an adverse effect as far as the roasting operation is concerned, and rather has an effect of raising the roasting temperature (see Fig. 9). The effects of $\mathrm{CaO}$ will be separately reported in detail.

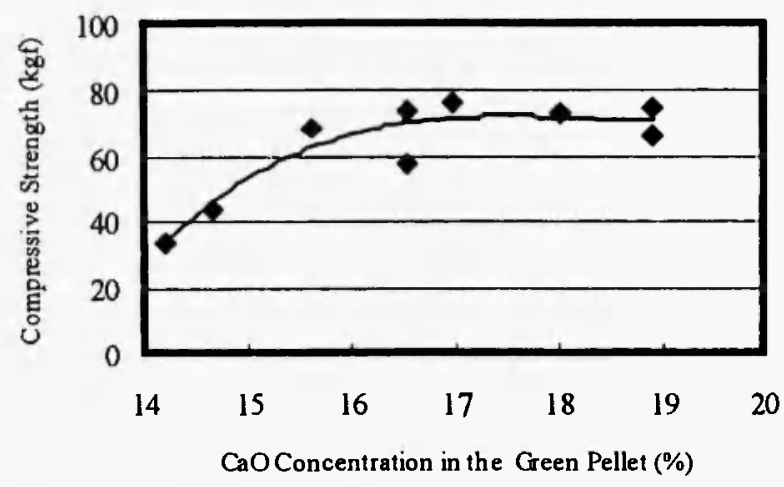

Fig. 9: Relation between $\mathrm{CaO}(\%)$ and sintered pellet strength 


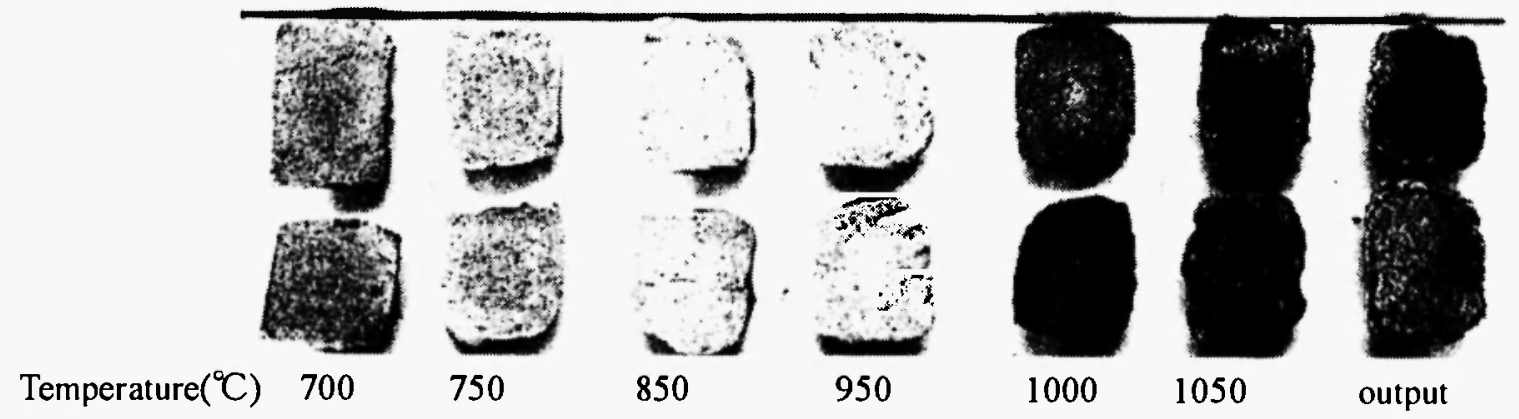

inside the kiln

Fig. 10: Photo of the pellet cross section in the roasting process

\subsection{Effect of temperature}

As shown in Fig. 5, the sintered pellet strength increases with the increase in the roasting temperature, as long as it does not cause any problem in the roasting process.

In order to grasp the progress of the roasting over time, pellets that were in different stages of roasting were directly sampled out of the kiln in the test operation and observed (Fig. 10). Sampling was performed using multiple sampling ports drilled in advance at specific positions in the test kiln. After temporarily halting the kiln rotation, pellets were taken out from the kiln bed layer. By closely observing the surfaces and cross sections of these pellets that were taken out in the midst of the roasting treatment, it was found that two types of melts are involved in the roasting operation that produces high-strength pellets and these melts play important roles in realizing such a high strength. One type of melt involved is alkaline metal chloride, which is melted and evaporated by the temperature raising. Part of the melt thus generated exhibits a phenomenon of covering the surfaces of the particles. The white part that is shown in the center of the pellet indicates this phenomenon. The $\mathrm{Na}$ and $\mathrm{K}$ component moves around within a pellet comparatively actively. In order to confirm such movement of $\mathrm{Na}$, $\mathrm{Al}_{2} \mathrm{O}_{3}$ pellets and soda ash mixture were roasted and subjected to EPMA surface analysis. A representative result is shown in Fig. II. It was found that the $\mathrm{Na}$ component moves around cleanly within the pellet. The other type of melt involved is $\mathrm{NaO}, \mathrm{FeO}$ and $\mathrm{SiO}_{2}$ etc., and a composite compound that has a comparatively (a)

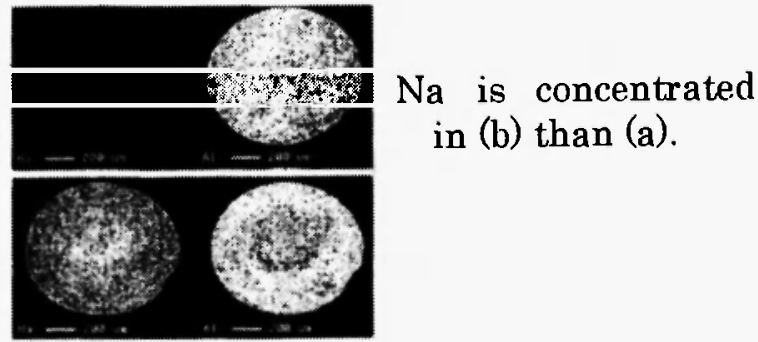

$\mathrm{Na}$

Al

Fig. 11: Photo of $\mathrm{Na}$ transition in the $\mathrm{Al}_{2} \mathrm{O}_{3}$ pellet cross section (EPMA surface analysis)

low melting temperature is generated. This process is confirmed by the fact that the color becomes blackgrayish subsequent to slag increasing as shown in Fig 10. and a small amount of melt is observable.

The observation shows that after pellets are charged into the kiln, the alkali salt contained in them starts melting at around $700{ }^{\circ} \mathrm{C}$. At the same time, $\mathrm{Na}$ and $\mathrm{K}$ evaporate while diffusing in the pellet, or decompose and generate $\mathrm{HCl}$ gas. This technology was developed utilizing a characteristic that $\mathrm{Na}$ is uniformly distributed by diffusion. It is an application of a special soda roasting technology that is basically applicable to a material formed into a pellet shape.

\subsection{Effect of reducing atmosphere}

As shown in Fig. 10, the cross section of a sintered pellet exhibits a different color according to its roasting 


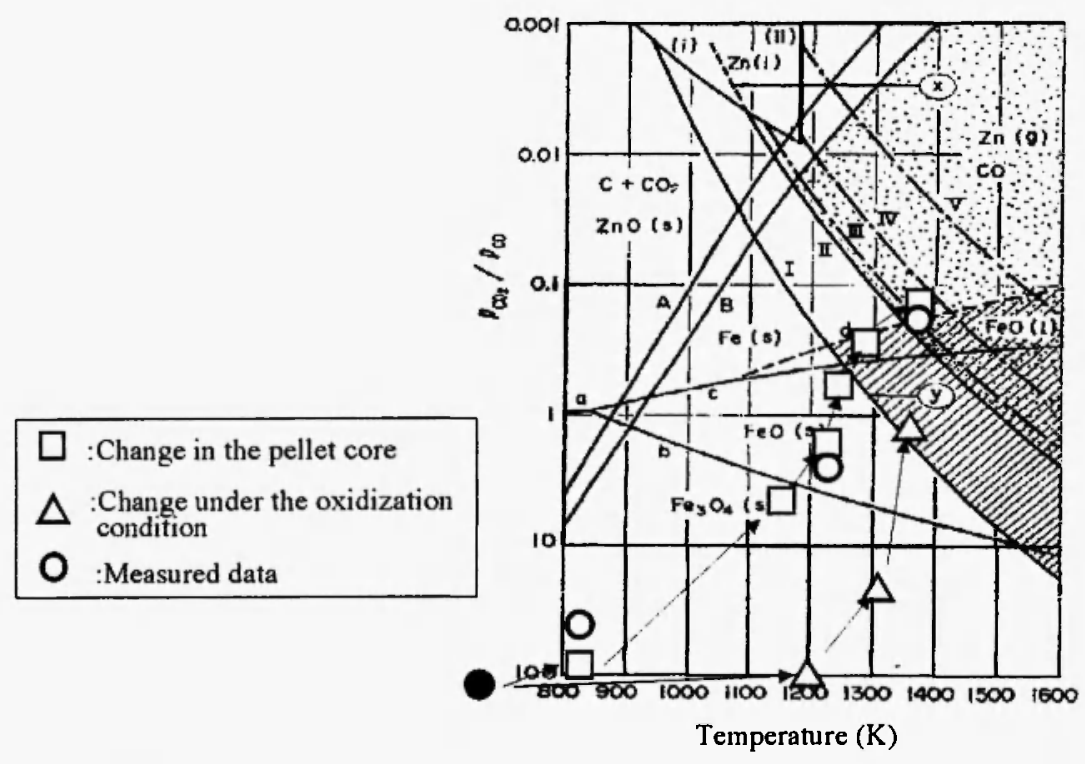

Fig.12: Transition of the atmosphere in the kiln bed layer

stage. The analytical investigation revealed that this phenomenon is caused by the diffusion of each ingredient as well as by the change in the form of iron contained in a pellet. When the reducing atmosphere is maintained, $\mathrm{Fe}_{2} \mathrm{O}_{3}$ in a pellet is reduced to $\mathrm{FeO}$, showing a black-grayish color. In this case, the sintered pellet exhibits a high strength. On the other hand. in an oxidizing atmosphere, $\mathrm{Fe}_{2} \mathrm{O}_{3}$ in a pellet remains unchanged, and thus the pellet maintains a rustybrownish color. In this case, the pellet strength is low.

The reducing process of the pellets sampled out of the kiln was analytically evaluated. The results are shown in Fig. 12 along with the gas analysis values. From these results, it is known that under a reducing condition, the reducing reaction starts taking place at a comparatively low temperature. The reducing reaction is considered to progress well into the stable metal $\mathrm{Fe}$ $\left(\mathrm{Fe}^{\mathrm{a}}\right)$ region, judging from the $\mathrm{Fe}^{\mathrm{a}}$ generation observed at a high temperature. This is in agreement with the gas analysis values indicated in the same figure.

Since the iron form has a large effect on the sintered pellet strength, the relation between the roasting condition and the $\mathrm{Fe}^{2+}(\mathrm{FeO}) / \mathrm{T}-\mathrm{Fe}$ ratio was investigated. The results are shown in Table 2 , which indicates that iron is reduced in a comparatively short period of time. Thus. it was confirmed that a sufficient
Table 2

Relation among $\mathrm{Fe}^{2 i}$ /total-Fe ratio, sintering temperature, and retaining time

$\mathrm{Fe}^{2 ;}$ total-Fe ratio (\%)

(Basic test)

\begin{tabular}{|c|c|c|c|c|}
\hline \multirow{2}{*}{$\begin{array}{l}\text { Retaining } \\
\text { time (min.) }\end{array}$} & \multicolumn{4}{|c|}{ Sintering temperature $\left({ }^{\circ} \mathrm{C}\right.$ ) } \\
\cline { 2 - 5 } & 950 & 1000 & 1050 & 1100 \\
\hline 5 & 79.3 & 79.3 & 70 & 99 \\
\hline 10 & 86.7 & 76.9 & 62.2 & 100 \\
\hline 20 & 83.1 & 74.7 & 60.7 & 100 \\
\hline
\end{tabular}

$\mathrm{N}_{2}$ gas flow, $5 \%$ coke addition.

amount of $\mathrm{FeO}$ is generated by giving a proper reducing condition.

The relation between the iron content and sintered pellet strength is shown in Fig. 12. The effect of adding hematite $\left(\mathrm{Fe}_{2} \mathrm{O}_{3}\right)$ is compared with that of adding slag in this figure. When the iron is added in the form of $\mathrm{Fe}_{2} \mathrm{O}_{3}$. it is preferable to add the iron content of more than around $8 \%$ in $\mathrm{Fe}_{2} \mathrm{O}_{3}$ equivalence. On the other hand, too much addition tends to decrease the pellet strength. Judging from the phase diagrams of $\mathrm{SiO}_{2}-\mathrm{Al}_{2} \mathrm{O}_{3}-\mathrm{Na}_{2} \mathrm{O}$ and $\mathrm{SiO}_{2}-\mathrm{Al}_{2} \mathrm{O}_{3}-\mathrm{FeO}$, presumably there exists a region where the melting point is comparatively low at a certain iron concentration level and therefore the iron concentration has a proper range for obtaining high- 
strength pellets. Issues related to the proper range of the iron concentration will be reported separately.

The iron is reduced in the roasting process and contributes to the reaction in the form of $\mathrm{FeO}$. Therefore it was expected that an additive that contains $\mathrm{FeO}$ would have a favorable effect. Fig. 13 also shows an instance where slag of non-ferrous smelter that contains iron in the form of $\mathrm{FeO}$ was used. It was verified that adding the slag as a $\mathrm{FeO}$ source has a more favorable effect on the pellet strength than adding the hematite $\left(\mathrm{Fe}_{2} \mathrm{O}_{3}\right)$. Further, adding the slag up to $15 \%$ in $\mathrm{Fe}_{2} \mathrm{O}_{3}$ equivalence induces no adverse effect on the pellet strength.

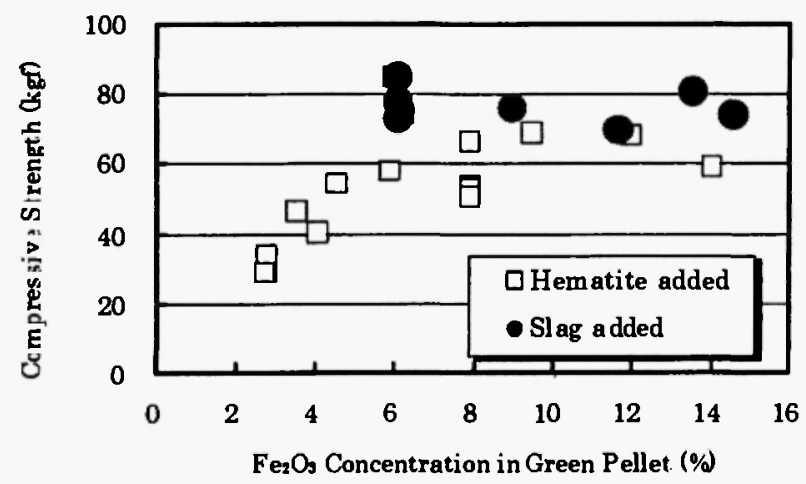

Fig. 13: Effect of $\mathrm{Fe}_{2} \mathrm{O}_{3}$ concentration on sintered pellet strength

Tests were also performed to confirm what effect adding a slag of non-ferous smelter has on the removal and stabilization of heavy metals. The results are shown in Table 3. Adding the slag that contained $\mathrm{Pb}$ led to the increase in the $\mathrm{Pb}$ concentration in the green pellets. Nevertheless, $\mathrm{Pb}$ was sufficiently removed from the sintered pellets by evaporation. In addition, elusion tests produced extremely favorable results. The elusion tests also confirmed that $\mathrm{Cd}$ and $\mathrm{Cr}$ were well stabilized. Thus, it was verified that the heavy metals contained in the slag are easily removed by evaporation and sufficiently stabilized by this roasting technology, which raises the expectation that this technology will be widely applied in the future.

\subsection{Stabilization of heavy metals}

With regard to the stabilization of heavy metals, the $X-R D$ revealed that the major compounds constituting a pellet are composite compounds composed of various oxides. During the process where these composite compounds are formied by sintering, presumably the heavy metals are metallurgically stabilized in the form of oxides. As the concentration levels of the residual heavy metals are extremely low, it is difficult to confirm their forms. However it is presumed that they remain in the sintered pellet in the form of oxides. The EPMA surface analysis exhibits that heavy metals such as $\mathrm{Pb}$ and $\mathrm{Zn}$ remain in the sintered pellets dispersed in extremely uniform manners. If these ingredients had remained in the form of volatile matters such as $\mathrm{PbCl} 2$, certain evidence of distributed concentration associated with volatilization would have been left behind in the pellet.

In addition to the elution tests reported above, crushed sintered pellets were subjected to the elution tests designated by the Japanese Ministry of the Environment (MOE). Also, the recirculating elution tests were performed at $\mathrm{pH} 4$ simulating acid rain. The results are shown in Table 4 . Even at pH4, sufficiently low values of heavy metals in the teste were obtained. Crushed pellets also produced excellent results. Thus, it was verified that the sintered pellets are comparatively

Table 3

Effect of slag addition on heavy metals removal and stabilization

\begin{tabular}{|ll|c|c|c|c|c|}
\hline \multirow{2}{*}{ Sample type } & Green pellet & \multicolumn{2}{|c|}{ Sintered pellet } & \multicolumn{3}{|c|}{ Elution amount (mg/l) } \\
\cline { 3 - 7 } & & Pb concentration (\%) & Pb concentration (\%) & $\mathrm{Pb}$ & $\mathrm{Cd}$ & $\mathrm{Cr}$ \\
\hline \multirow{2}{*}{ slag A addition } & $(1)$ & 0.19 & 0.01 & 0.007 & $<0.001$ & 0.022 \\
\cline { 2 - 7 } & $(2)$ & 0.17 & 0.011 & 0.005 & $<0.001$ & 0.01 \\
\hline \multirow{2}{*}{ slag B addition } & $(1)$ & 0.38 & 0.005 & 0.001 & $<0.001$ & 0.01 \\
\cline { 2 - 7 } & $(2)$ & 0.42 & 0.006 & 0.003 & $<0.001$ & 0.012 \\
\hline
\end{tabular}


Table 4

Elution test results

\begin{tabular}{|l|c|c|c|c|}
\hline \multirow{2}{*}{ Analyzed item } & Unit & \multicolumn{2}{|c|}{ Recirculating elution test (pH4) } & $\begin{array}{c}\text { MOE Notification } \\
\text { No. 46 test }\end{array}$ \\
\cline { 3 - 5 } & & Not crushed & Crushed & Crushed \\
\hline Final $\mathrm{pH}$ & & 4.02 & 4.06 & 9.91 \\
\hline $\mathrm{Pb}$ & $\mathrm{mg} / \mathrm{L}$ & 0.002 & $<0.001$ & $<0.001$ \\
\hline $\mathrm{Cd}$ & $\mathrm{mg} / \mathrm{L}$ & 0.001 & $<0.001$ & $<0.001$ \\
\hline $\mathrm{Cr}{ }^{+0}$ & $\mathrm{mg} / \mathrm{L}$ & $<0.01$ & $<0.01$ & $<0.01$ \\
\hline $\mathrm{As}$ & $\mathrm{mg} / \mathrm{L}$ & 0.0001 & 0.0001 & 0.0007 \\
\hline $\mathrm{Se}$ & $\mathrm{mg} / \mathrm{L}$ & $<0.0003$ & $<0.0003$ & 0.0003 \\
\hline $\mathrm{T}-\mathrm{Hg}$ & $\mathrm{mg} / \mathrm{L}$ & $<0.00005$ & $<0.00005$ & $<0.00005$ \\
\hline $\mathrm{Na}$ & $\mathrm{mg} / \mathrm{L}$ & 22.7 & - & 17.5 \\
\hline $\mathrm{K}$ & $\mathrm{mg} / \mathrm{L}$ & 7.8 & - & 6.6 \\
\hline $\mathrm{Ca}$ & $\mathrm{mg} / \mathrm{L}$ & 19 & - & 3.8 \\
\hline $\mathrm{Cl}$ & $\mathrm{mg} / \mathrm{L}$ & 9.2 & - & 27.8 \\
\hline $\mathrm{SO}{ }_{4}$ & $\mathrm{mg} / \mathrm{L}$ & 10 & - & 8.7 \\
\hline
\end{tabular}

uniform and the heavy metals are fixed within the pellet well stabilized. Similar elution tests of the pellets to which smelting slag was added as an iron source also produced favorable results as shown in Table 3.

Next, the relation between the residual heavy metal amount and the elution amount was investigated. If the entire amount of residual heavy metals elutes out of the pellets, the elution amount is expected to become extremely large. Therefore, in developing a technology for making heavy metals harmless, the high-level stabilization of the residual heavy metals is a key in addition to their thorough removal. The basic test results shown in Table 5 demonstrate that all the elution amounts were less than $1 \mathrm{mg} / \mathrm{l}$ despite the variance in the residual amounts. Thus, it is apparent that the elution amount is also affected by factors other than the residual amount. However, the details are still unknown in the case of Table 5.

Table 6 shows the relation between the residual $\mathrm{Zn}$ amount and elution amount in the case where the residual $\mathrm{Zn}$ amount is comparatively large. When the roasting temperature was varied from 950 to $1050{ }^{\circ} \mathrm{C}$, the residual amount stayed nearly at a same level, but the elution amount was widely different. The elution amount rapidly decreases with the increase in the retaining time as well as with the increase in the roasting temperature to $1100{ }^{\circ} \mathrm{C}$. These results clearly demonstrate that heavy metals contained in the pellets are well stabilized by the progress of the sintering.

\section{CONCLUSIONS}

1) High-strength pellets are obtained through a sintering process where the liquid phase is involved.

2) The molten body of alkali salt and that of slag play important roles in obtaining a stable high strength, and there exists a certain compositional range that is in conformity with a roasting temperature.

3) For facilitating the sintering process, it is indispensable that the iron is in the form of $\mathrm{FeO}$. Also, a certain amount of reducing material needs to be added.

4) The residual heavy metals are metallurgically fixed and stabilized through forming composite compounds with non-metallic compounds such as $\mathrm{SiO}_{2}, \mathrm{Al}_{2} \mathrm{O}_{3}$ and $\mathrm{CaO}$.

5) In a series of roasting processes, the alkali salt plays an effective role in obtaining a favorable composition and in removing the heavy metals. 
Table 5

Relation between residual $\mathrm{Pb}$ amount and elution amount

Elution amount $(\mathrm{mg} / \mathrm{l})$

\begin{tabular}{|c|c|c|c|c|c|c|c|c|}
\hline \multirow{2}{*}{$\begin{array}{c}\text { Retaining } \\
\text { time (min.) }\end{array}$} & \multicolumn{9}{|c|}{ Sintering temperature $\left({ }^{\circ} \mathrm{C}\right)$} \\
\cline { 2 - 9 } & \multicolumn{2}{|c|}{950} & \multicolumn{2}{|c|}{1000} & \multicolumn{2}{c|}{1050} & \multicolumn{2}{c|}{1100} \\
\cline { 2 - 9 } & $\begin{array}{c}\text { Residual } \\
\text { amount } \\
(\%)\end{array}$ & $\begin{array}{c}\text { Elution } \\
\text { amount } \\
(\mathrm{mg} / \mathrm{l})\end{array}$ & $\begin{array}{c}\text { Residual } \\
\text { amount } \\
(\%)\end{array}$ & $\begin{array}{c}\text { Elution } \\
\text { amount } \\
(\mathrm{mg} / \mathrm{l})\end{array}$ & $\begin{array}{c}\text { Residual } \\
\text { amount } \\
(\%)\end{array}$ & $\begin{array}{c}\text { Elution } \\
\text { amount } \\
(\mathrm{mg} / \mathrm{l})\end{array}$ & $\begin{array}{c}\text { Residual } \\
\text { amount } \\
(\%)\end{array}$ & $\begin{array}{c}\text { Elution } \\
\text { amount } \\
(\mathrm{mg} / \mathrm{l})\end{array}$ \\
\hline \multirow{3}{*}{5} & 0.27 & $<1$ & 0.17 & $<1$ & 0.07 & $<1$ & 0.03 & $<1$ \\
\cline { 2 - 10 } & 0.25 & $<1$ & 0.2 & $<1$ & 0.07 & $<1$ & 0.03 & $<1$ \\
\hline \multirow{2}{*}{10} & 0.19 & $<1$ & 0.07 & $<1$ & 0.02 & $<1$ & 0.03 & $<1$ \\
\cline { 2 - 9 } & 0.19 & $<1$ & 0.11 & $<1$ & 0.03 & $<1$ & 0.02 & $<1$ \\
\hline \multirow{2}{*}{20} & 0.1 & $<1$ & $<0.02$ & $<1$ & $<0.02$ & $<1$ & $<0.02$ & $<1$ \\
\cline { 2 - 9 } & 0.08 & $<1$ & 0.02 & $<1$ & $<0.02$ & $<1$ & $<0.02$ & $<1$ \\
\hline
\end{tabular}

$\mathrm{N}$, gas atmosphere

Table 6

Relation among $\mathrm{Zn}$ elution amount, roasting temperature, and retaining time (Basic test)

\begin{tabular}{|c|c|c|c|c|c|c|c|c|}
\hline \multirow{3}{*}{$\begin{array}{l}\text { Retaining } \\
\text { time (min.) }\end{array}$} & \multicolumn{8}{|c|}{ Baking tempetature $\left({ }^{\circ} \mathrm{C}\right)$} \\
\hline & \multicolumn{2}{|c|}{950} & \multicolumn{2}{|c|}{1000} & \multicolumn{2}{|c|}{1050} & \multicolumn{2}{|c|}{1100} \\
\hline & $\begin{array}{c}\text { Residual } \\
\text { amount } \\
(\%)\end{array}$ & $\begin{array}{c}\text { Elution } \\
\text { amount } \\
(\mathrm{mg} / \mathrm{l}) \\
\end{array}$ & $\begin{array}{c}\text { Residual } \\
\text { amount } \\
(\%) \\
\end{array}$ & $\begin{array}{c}\text { Elution } \\
\text { amount } \\
(\mathrm{mg} / \mathrm{l})\end{array}$ & $\begin{array}{c}\text { Residual } \\
\text { amount } \\
(\%)\end{array}$ & $\begin{array}{c}\text { Elution } \\
\text { amount } \\
(\mathrm{mg} / \mathrm{l}) \\
\end{array}$ & $\begin{array}{c}\text { Residual } \\
\text { amount } \\
(\%)\end{array}$ & $\begin{array}{c}\text { Elution } \\
\text { amount } \\
(\mathrm{mg} / \mathrm{l}) \\
\end{array}$ \\
\hline \multirow{2}{*}{5} & 1.48 & 49 & 1.59 & 74 & 1.52 & 100 & 0.99 & $<1$ \\
\hline & 1.54 & 76 & 1.5 & 140 & 1.54 & 99 & 1.11 & $<1$ \\
\hline \multirow{2}{*}{10} & 1.59 & 5.6 & 1.55 & 42 & 1.42 & 52 & 0.95 & $<1$ \\
\hline & 1.56 & $<1$ & 1.57 & 35 & 1.47 & 2.5 & 1.08 & $<1$ \\
\hline \multirow{2}{*}{20} & 1.57 & 1.4 & 1.59 & $\therefore 1$ & 1.45 & $<1$ & 0.82 & $<1$ \\
\hline & 1.59 & $<1$ & 1.52 & $<1$ & 1.45 & $<1$ & 0.71 & $<1$ \\
\hline
\end{tabular}

$\mathrm{N}_{2}$ gas atmosphere 


\section{ACKNOWLEDGEMENT}

We would like to express our gratitude to the cooperation extended to this research by various municipal governments and universities, the Center of Eco-Mining, NEDO, and many other related organizations and personnel.

\section{REFERENCES}

I. J. Takahashi, K. Tomoda, and M. Matsuno, Proceedings MMIJ Autumn Meeting, D3-2, pp. 49$52(2000)$

2. J. Takahashi, K. Tomoda, and M. Matsuno, Proceedings MMIJ Autumn Mecting, D4-2, pp. 229-232 (2001)

3. K. Iwasawa, S. Yamaguchi, T. Okabe, and M. Maeda, Proceedings MMIJ Autumn Meeting, D54. pp.261-263 (2001)

4. J. Takahashi, K. Tomoda, and M. Matsuno, TMS Fall 2002 Extraction and Processing Division Meeting, vol.2, pp.473-480 (2002)

5. S. Yamaguchi, K. Iwasawa, and M. Maeda, TMS
Fall 2002 Extraction and Processing Division Meeting, vol.2, pp.457-462 (2002)

6. M. Matsuno, and K. Tomoda. TMS 132 Annual Meeting \& Exhibition Yazawa International Symposium, vol.1, pp.1093-1101 (2003)

7. M. Matsuno. K. Tomoda and J. Takahashi, Proceedings MMIJ Annual Meeting, (11)3618. pp.226-227 (2003)

8. K. Kawamoto. K. Tomoda and M. Matsuno. Jupun Society of Waste Management Experts (.JSWME). B-8-8 (2003)

9. M. Matsuno, K. Tomoda. K. Kawamoto and T. Nakamura, "The new proposal of fly ash treatment and practical tests of pilot plant", JSWME (in press).

10. M. Matsuno, K. Tomoda and T. Nakamura, "Volatilization mechanism of $\mathrm{Pb}$ from fly ash in a municipal waste incinerator" Materials Transactions, 44 (12), 2481-2488 (2003).

11. M. Matsuno, K. Tomoda and T. Nakamura "Separation by evaporation of various metals in incinerator fly ash by kiln-roasting method", MMIJ (to be submitted). 